\title{
Clinical observation on the treatment of chronic refractory pressure ulcer with combined shock wave and exercise therapies
}

\begin{abstract}
Object: To observe the clinical efficacy of combined application of extracorporeal shock wave and exercise therapy in the treatment of refractory stress injury.

Method: 36 patients with pressure ulcer were randomized into three groups: conventional treatment group, shock wave group, combined shock wave and exercise therapy group. Judgment was based on evaluating the scores of pressure ulcer healing (PUSH3.0) and the ability of daily living activities (ADL).

Results: The score of the combined shock wave and exercise therapy group was better than that of the other two groups $(\mathrm{P}=0.000)$, and the score of the shock wave group was better than that of the conventional group with statistical significance $(\mathrm{P}=0.000)$

Conclusion: Combined extracorporeal shock wave and exercise therapies can improve the wound healing rate, the overall functional status of patients and the ability of daily living activities (ADL)
\end{abstract}

Keywords: chronic refractory pressure ulcer, shock wave, exercise therapy
Volume 5 Issue 2 - 2020

\author{
Xu Yanzhong,' Wu Zhonghua, ${ }^{2}$ Qiao Feiei, ${ }^{\prime}$ \\ Qiu Xiaohong,' Wang Xin, ${ }^{2}$ Yu Changlong ${ }^{2}$ \\ 'Rehabilitation Department, Jinhua Rehabilitation Hospital, \\ China \\ ${ }^{2}$ Orthopedic Department, Far East Horizon Medical Group, \\ China
}

\begin{abstract}
Correspondence: Wang Xin, Orthopedic Department, Far East Horizon Medical Group, No.9 Yaojiang Road, Shanghai City, China, Tel +86013522263 I03, Fax +8602/ 389/3000, Email wangx|2@|26.com

Yu Changlong, Orthopedic Department, Far East Horizon Medical Group, No.9 Yaojiang Road, Shanghai City, China, Tel +86013501831743 , Fax +8602138913000

Email ycl12@vip.sina.com
\end{abstract}

Received: March 10,2020 | Published: March 18, 2020

Abbreviations: PUSH3.0, the scores of pressure ulcer healing; ADL, the ability of daily living activities; MBI, modified barthel index; NPUAP, national pressure ulcer advisory panel

\section{Introduction}

Chronic refractory pressure ulcer refers to the chronic refractory wound ulcer ${ }^{1}$ that occurs when the wound is not healed within one month. It is a common complication of chronic disease and bedridden patients over 60 years old. ${ }^{2}$ The direct cause of pressure ulcer is the movement disorder of bedridden patients and the compromised maximal oxygen uptake. The pressure ulcer affect the patients' motor function, and the patients' ability of daily life activities is also apparently compromised. Therefore, on the basis of conventional debridement and dressing change, the patients with chronic pressure ulcer were treated with shock wave in combination with exercise therapy. The report is as followings.

\section{Material and methods}

1. From December 2017 to December 2019, 36 patients with chronic refractory pressure ulcer were admitted to Jinhua rehabilitation hospital. The inclusion criteria were as followings: 1)the diagnosis of refractory pressure ulcer in accordance with the guidelines of Chinese practical rehabilitation medicine,

2. The total score of pressure ulcer healing subscale (push3.0) designed by the national pressure ulcer expert group (NPUAP) $\geq 11$ points,

3. No necrotic tissue in the wound and exudates for 24 hours $\leq 5 \mathrm{ml}$
4. serum Albumin $\geq 30 \mathrm{~g}$. Exclusion criteria: 1) severe heart disease, 2) implantation of pacemaker, 3) incurable hemorrhagic diseases and coagulopathy, 4) administration of immunosuppressant, 5) patients with various tumor, 6) patients with thrombosis. The duration of the disease was 3-12 months averaged as 4.6 months, including 13 males and 23 females, aged from 65 to 92 years, averaged as 81 years. Among them, 15 cases were hemiplegic, with 11 cases fracture, 5 cases Parkinson's syndrome and 5 cases senile dementia.

\section{Treatment}

Conventional treatment group: common surgical disinfection, debridement and dressing change

Shockwave group: on the basis of the same surgical disinfection, debridement and dressing change, shockwave therapy was applied around the pressure ulcer wound, with the energy flow density of $0.2-$ $0.38 \mathrm{MJ} / \mathrm{mm} 2,1600-2000$ shocks per time, frequency of $10-15 \mathrm{~Hz} / \mathrm{s}$, pressure of 1.6-3.0 bar, once every 5 days, for 4 weeks.

Combined shock wave and exercise therapy group: In addition to conventional therapy and shock wave therapy, exercise therapy was added: 1) breathing training, abdominal breathing training, training of abdominal muscle strength and chest activity for 10 minutes each time 1 time/day, 2) training of passive limb joint mobility, 3) training of limb muscle strength: when muscle strength is 1-3 levels, barehanded assistance is used for active movement or on the sliding surface. When muscle strength is above 3 levels, the correct body position and posture are taken for counter-gravity position to prevent compensatory movement; when muscle strength is above 4 levels, 
barehanded exercise, weight bearing and friction are employed for resistance training. Repeat each action 5-10 times, twice a day, 4) Electric standing up bed training: beginning from 30 degrees and increasing gradually to 70 degrees, 20 minutes duration each time, twice a day, 5) wheelchair decompression: it is aimed to prevent pressure ulcer for patients in wheelchairs for long time, and the hip decompression should be carried out every 30 minutes with the armrest of the wheelchair supported by hand, so that the hip can be suspended and maintained for about 15 minutes. At the same time, attentions should be paid to the pressure of all bone apophysis.

\section{Observation index and evaluation standard}

i. Total score of pressure ulcer: scoring each pressure ulcer by using push3.0 designed by NPUAP 7, 14 and 28 days after treatment.

ii. Activities of daily living (ADL) were assessed by modified Barthel Index (MBI) ${ }^{3}$

Table I Push 3.0 score comparison (mean \pm standard deviation) iii. SPSS 18.0 software was used for statistical analysis of the data obtained, and the measurement data was expressed by (mean \pm standard deviation), compared with variance analysis $\mathrm{F}$ test and SNK-t test; $\mathrm{P}<0.05$, it was determined to be statistically significant.

\section{Results}

Push3.0 scores of the three groups on the $7^{\text {th }}, 14^{\text {th }}$ and $28^{\text {th }}$ day of treatment: the scores of the shock wave group and the combined shock wave and exercise group decreased gradually, and the scores of the combined shock wave and exercise group decreased more significantly on the $28^{\text {th }}$ day of treatment. $(\mathrm{F}=70.691, \mathrm{P}=0.000)$. Among them, the score of shock wave and exercise group and the convention group was statistically significant $(\mathrm{P}=0.000)$, the score of shock wave group and the convention group was statistically significant $(\mathrm{P}=0.000)$, as shown in Table 1.

\begin{tabular}{|c|c|c|c|c|c|}
\hline Group & $\begin{array}{l}\text { Hemiplegic/fracture/parkinson's } \\
\text { syndrome/senile dementia }\end{array}$ & $\begin{array}{l}\text { Before } \\
\text { treatment }\end{array}$ & $\begin{array}{l}\text { 7d after } \\
\text { treatment }\end{array}$ & $\begin{array}{l}\text { I4d after } \\
\text { treatment }\end{array}$ & $\begin{array}{l}\text { 28d after } \\
\text { treatment }\end{array}$ \\
\hline convention & $5 / 4 / 1 / 2$ & $11.20 \pm 2.10$ & $\mid I .17 \pm 3.11$ & $10.73 \pm 3.83$ & $9.00 \pm 4.00$ \\
\hline shock wave & $4 / 4 / 2 / 2$ & II. $30 \pm 2.53$ & $9.74 \pm 3.15$ & $8.73 \pm 3.86$ & $4.10 \pm 4.24 *$ \\
\hline $\begin{array}{l}\text { shock wave and exercise } \\
\text { therapy }\end{array}$ & $6 / 3 / 1 / 2$ & $11.25 \pm 2.13$ & $9.52 \pm 3.36$ & $7.30 \pm 2.12$ & $2.85 \pm 1.30 *$ \\
\hline
\end{tabular}

Note The results are presented as mean \pm standard deviation *the score of shock wave and exercise group and the convention group were statistically significant $(P=0.000)$, the score of shock wave group and the convention group were statistically significant $(P=0.000)$,

There were statistical difference in MBI score of ADL among the three groups $(\mathrm{F}=68.074, \mathrm{P}=0.000)$ The MBI score of $\mathrm{ADL}$ in the shock wave combined with exercise therapy group was significantly improved compared with that in the conventional group, with a statistically significant difference $(\mathrm{P}=0.000$. The difference between the combined with exercise therapy group and shock wave group was statistically significant $(\mathrm{P}=0.002)$.as shown in Table 2 .

Table 2 MBI score comparison (mean \pm standard deviation)

\begin{tabular}{|c|c|c|c|}
\hline Group & $\begin{array}{l}\text { Hemiplegic/fracture/parkinson's } \\
\text { syndrome/senile dementia }\end{array}$ & Before treatment & After treatment \\
\hline convention & $5 / 4 / 1 / 2$ & $26.20 \pm 2.10$ & $30.77 \pm 3.11$ \\
\hline shock wave & $4 / 4 / 2 / 2$ & $24.30 \pm 2.53$ & $40.74 \pm 3.15 \#$ \\
\hline shock wave and exercise therapy & $6 / 3 / 1 / 2$ & $25.75 \pm 2.13$ & $60.52 \pm 6.36^{*}$ \\
\hline
\end{tabular}

Note *The results are presented as mean \pm standard deviation. *The difference between the shock wave combined with exercise therapy group and the conventional group, was statistically significant $(\mathrm{P}=0.000)$. \# The difference between the combined with exercise therapy group and shock wave group was statistically significant $(\mathrm{P}=0.002)$.

\section{Discussion}

The treatment of chronic wound surface with shock wave has been reported both at home and abroad, but the parameters, of which wound is suitable for ESWT treatment are different, such as energy, frequency and cycle. ${ }^{4}$ The wound selected in this study was clean and pale: no necrotic tissue, exudates for 24 hours $\leq 5 \mathrm{ml}$, push 3.0 score of pressure ulcer healing $\geq 11$ points. This kind of wound can be characterized as: less capillary network, tissue adhesion, ischemia and hypoxia, few fresh granulation tissue growth and poor wound healing for long time. The principle of non focused low-energy shock wave is to harness the acoustic energy of shock wave, which can be transformed into mechanical energy to facilitate angiogenesis, the proliferation of fibroblasts, the production of matrix, the contraction of wound edge, and the extension of epidermal cells to cover the wound surface, so as to achieve the purpose of treatment. Applying the effect of shock wave on the relief of tissue adhesion, tensile stress can relieve tissue and accelerate the microcirculation of capillaries; compressive stress can make cells elastic and increase the oxygen uptake of cells. In the clinical treatment, after the shock wave treatment, it was observed that local wound tissue was fresh, the pale tissue turned red, the granulation tissue grew, the deep space and sinuses tract gradually closed, and the peripheral epithelial tissue grew obviously. During the treatment period, it was not observed that the wound exudation increased, and the granulation tissue proliferated poorly. 
The etiology of pressure ulcer is that the patient's own weight is constantly exerted upon the most prominent part of the body. Reducing, dispersing, relieving the pressure on the wound and avoiding repeated pressure are the premise of curing pressure ulcer. ${ }^{5}$ In this study, we used sports therapy to change the bad position of the wound under continuous pressure, relieve the most direct cause and pathogenic factors of pressure ulcer, and improve the tolerance of local skin and soft tissue to pressure and shear force; in patients who underwent shock wave therapy and sports therapy at the same time, the time of wound healing was significantly shortened, and the healing rate was significantly improved. Exercise therapy can promote wound healing, which is consistent with the conclusion drawn by other basic medical researchers. Exercise therapy can improve the blood supply and oxygen supply of wound by improving the maximum oxygen uptake ability of patients. At the same time, it can promote collagen synthesis and capillary neogenesis, accelerate wound healing. ${ }^{6}$ Exercise therapy can facilitate the blood and lymph circulation of the whole body and the wound, promote the absorption of local inflammatory metabolites, and accelerate the transition from the inflammatory reaction stage to the value-added repair stage of the wound. ${ }^{7}$ Regular active and passive training of the whole body and limbs can significantly promote the cardiopulmonary function, exercise and oxygen uptake ability, appetite, digestion, nutrients absorption and immunity of bedridden patients with motor disorder. ${ }^{8}$ In this study, through active and effective exercise, the patients is gradually able to turn over, sit up, stand under the assistance, walk, eat and dress, etc., which significantly improve the ability of daily life activities of patients.

\section{Conclusion}

To sum up, for the clean, pale and hard to heal wounds, the combination therapy of shock wave and exercise can effectively facilitate the healing process of wounds, promote the motor ability of patients, improve the patients' quality of life and lay good basis for recurrence prevention of pressure ulcer. In addition, shockwave therapy combined with exercise therapy is simple and easy to operate, and it is a feasible and effective treatment option for the treatment of chronic wounds in the community.

\section{Funding}

None.

\section{Acknowledgements}

None.

\section{Conflicts of interest}

The authors declare no conflicts of interest.

\section{References}

1. Fu Xiaobing. Diabetic foot and its related chronic refractory wound. 2nd ed. Beijing: People's military medical press, 2013:6-8.

2. Aygor HE, Sahin S, Sozen E, et al. Features of pressure ulcers in hospitalized older adults. Adv Skin Wound Care. 2014,27(3):122-126.

3. Nandengkun, GuoTiecheng. Clinical guidelines of rehabilitation medicine. Beijing: Science Press, 1999:373.

4. Zhao J, Xue Y, Yu J, et al. Progress in the mechanism of extracorporeal shock wave therapy in promoting wound healing. Chinese Journal of burn. 2015;31(4):315-317.

5. Linder-Granz E, Scheinowitz M. Yizhar Z. et al. How do normals move during prolonged wheel chair-sitting?. Technol Health care. 2007;15(3):195-202.

6. Craft LL, Perna FM. The benefitS of exercise for the clinically depressed. Prim Care Companion J Clin Psychiatry. 2004;6(3):104-111.

7. Keylock K, Young H. Delayed wound healing: can exercise accelerate it?. Int J Exerc Sci. 2010;3(3):70-78.

8. QuJinyu, Yu Changlong. Practical sports medicine. 4th ed. Peking University Medical Press, 2003:965-967. 